\title{
LOS RECORDATORIOS \\ DE LOS DESAPARECIDOS \\ DURANTE LA ÚLTIMA \\ DICTADURA ARGENTINA (1976- \\ 1983): ANÁLISIS CRÍTICO \\ DEL GÉNERO
}

\author{
OS RECORDATÓRIOS DOS DESAPARECIDOS DURANTE A ÚLTIMA DITADURA \\ ARGENTINA (1976-1983): ANÁLISE CRÍTICA DO GÊNERO
}

THE REMINDER OF THE MISSING PEOPLE DURING THE LAST ARGENTINE DICTATORSHIP (1976-1983): CRITICAL ANALYSIS OF THE GENRE

Graciela Mazur Geinses* Universidad de Buenos Aires

RESUMEN: En este artículo, se analiza un género discursivo que surgió, aproximadamente, en el año 1988: el recordatorio de los desaparecidos durante la última dictadura argentina (1976-1983). Se utiliza el enfoque presentado por Meurer (2005), el cual analiza el género desde las categorías propuestas por Fairclough (1992) para el Análisis Crítico del Discurso. El recordatorio de los desaparecidos es un género híbrido, ya que posee algunas de las características de varios géneros discursivos. Estos son en primer lugar, los tradicionalmente relacionados con la circunstancia de la muerte, en segundo lugar, los que podríamos denominar "géneros de la memoria", asociados al recuerdo de las víctimas del terrorismo de estado; y en tercer lugar, los avisos de búsqueda de

*Licenciada en Letras y Profesora de Enseñanza Media y Superior en Letras por la Universidad de Buenos Aires (U.B.A.). Actualmente es profesoradel I.S.F.D. No 1 de Avellaneda y del I,S.P. Joaquín V . González de la Ciudad de Buenos Aires. Inscripta en la Maestría de Análisis del Discurso(U.B.A.) E-mail:gracielamazurgeinses@yahoo.com.ar. 
paradero de personas, fuera del contexto de una dictadura. El análisis que aquí se realiza se centra especialmente en los recordatorios que Estela Barnes de Carlotto, la presidenta de la Asociación “Abuelas de Plaza de Mayo", escribió para su hija Laura Carlotto, detenida-desaparecida durante el último gobierno militar en Argentina.

PALABRAS CLAVE: Recordatorio de desaparecido. Análisis Crítico de Géneros. Género híbrido.

RESUMO: Neste artigo, analisa-se um gênero discursivo surgido aproximadamente no ano 1988: o recordatório de desaparecido durante a última ditadura argentina (1976-1983). Utiliza-se a abordagem apresentada por Meurer (2005), que analisa o gênero desde as categorias propostas por Fairclough (1992) para a Análise Crítica do Discurso. O recordatório de desaparecidos é um gênero híbrido, pois possui algumas das características de vários gêneros discursivos. Estes são, em primeiro lugar, aqueles tradicionalmente relacionados à circunstância da morte e, em segundo lugar, , o que poderíamos chamar "gêneros da memória", associados à memória das vítimas do terrorismo de Estado; além disso, apresentam a busca de informações sobre o paradeiro de pessoas, fora do contexto de uma ditadura. A análise realizada aqui enfoca especialmente nos recordatórios que Estela Barnes de Carlotto, presidente da Associação "Avós da Plaza de Mayo", escreveu para sua filha Laura Carlotto, detida-desaparecida durante o último governo militar na Argentina.

PALAVRAS CHAVE: Recordatórios de desaparecidos. Análise crítica de gênero. Gênero híbrido.

ABSTRACT: In this article we analyze a discursive genre emerged approximately in the year 1988: The reminder of the missing people during the last argentine dictatorship (1976-1983). We use the approach presented by Meurer (2005), which analyzes the genre from the categories proposed by Fairclough (1992) for a critical discourse analysis. The reminder of the missing people is a hybrid genre, since it possesses some of the characteristics of several discursive genres. First, these are those traditionally related to the circumstances of death; secondly, those which are called "memorial genres", associated with the remembrance of the victims of state terrorism; and, thirdly, the search for notices of a persons' whereabouts, outside the context of a dictatorship. The analysis carried out here focuses especially on the reminders that Estela Barnes de Carlotto, president of the association "grandmothers of plaza de mayo", wrote for her daughter Laura Carlotto, a disappeared-detainee who vanished during the last military government in Argentina.

KEYWORDS: Reminders of missing people. Critical genre analysis. Hybrid genre.

\section{INTRODUCCIÓN}

El recordatorio de los desaparecidos es un género que surge en Argentina aproximadamente en el año 1988, cuando los parientes de los desaparecidos durante la última dictadura militar (1976-1983), varios años después del fin de esta, empiezan a publicar en el diario Página 12 pequeños recuadros que los recuerdan y los honran. El objetivo del artículo es analizar las características y particularidades del recordatorio de desaparecido como género, basándonos en el enfoque de Meurer (2005), el cual analiza el género desde las categorías propuestas por Fairclough (1992) para el Análisis Crítico del Discurso. Es decir, teniendo en cuenta que el recordatorio como género no sólo supone un conjunto de convenciones relativamente estables, sino también representa una actividad social, e implica cuestiones sociales en su producción, distribución, consumo e interpretación (FAIRCLOUGH, 1992 p.161 apud MEURER, 2005, p.81) $)^{1}$.

La fundamentación para trabajar con el enfoque de Meurer (2005) se encuentra en la afirmación que este autor realiza: "Una razón esencial para la integración del Análisis Crítico del Discurso a los estudios de géneros textuales son las posibilidades teóricas y metodológicas que crea para ir más allá de las regularidades de los géneros y explorar también su relevancia con respecto a lo social" (FREEDMAN; MEDWAY, 1994b; MEURER, 2005, p. 105).

Los recordatorios que vamos a analizar dan cuenta del genocidio ocurrido en el país, y por eso mismo, son contestarios, cuestionadores del "statu quo", de la impunidad, de las versiones hegemónicas de la historia. En ese sentido, como afirma Bonini

\footnotetext{
${ }^{1}$ Todos los textos citados escritos en portugués tienen traducción mía.
} 
(2013, p. 114) veremos que el Análisis Crítico del Género también puede ser pensado como una forma de investigar las prácticas de liberación.

En este artículo nos centraremos en los recordatorios publicados en el diario Página 12 por la presidenta de la Asociación "Abuelas de Plaza de Mayo”, Estela Barnes de Carlotto, para recordar a su hija, Laura Carlotto, así como reclamar por justicia y por la aparición de su nieto, nacido en cautiverio.

La selección de este corpus se basa en varias cuestiones, una de índole práctica se relaciona con que los lectores pueden acceder en la web a la totalidad de los recordatorios publicados por Carlotto debido a su notoriedad pública (veintisiete recordatorios, de 1988 a 2014), a diferencia de los recordatorios de otros desaparecidos, donde sólo es posible hallar algunos de los publicados. Además, es interesante este recorrido diacrónico, que nos permite seguir de alguna manera la biografía de Laura Carlotto, que más allá de sus particularidades, también es representativa de las historias de muchos desaparecidos, y de la misma historia del país. Asimismo, en esa selección de recordatorios es posible encontrar una muestra de la mayoría de las variantes de este género discursivo. Según la perspectiva adoptada para abordar este género: "El Análisis crítico del discurso desarrollado por Fairclough propone que cada evento discursivo sea analizado desde tres ángulos o dimensiones que se complementan: como texto, como práctica discursiva, y como práctica social, buscando respectivamente una descripción, una explicación y una interpretación” (MEURER, 2005, p. 93).

Además, en el mencionado texto se afirma que: "Una ventaja del abordaje tridimensional de Fairclough es que el análisis de los textos puede tener diferentes 'puntos de entrada', podemos iniciar el análisis por cuestiones de cuño textual, como de prácticas discursivas, o de prácticas sociales. Lo más importante todavía es que esos tres niveles de análisis se complementan y no deben, por lo tanto, ser vistos como compartimentos estancos" (MEURER, 2005, p. 101).

Esto significa que podemos iniciar el análisis por cualquiera de las tres dimensiones, que son separadas para el análisis, pero remiten unas a otras, y funcionan simultáneamente. Por ejemplo, la identidad social de los desparecidos, y especialmente de Laura Carlotto se relaciona con la práctica social, pero este tema lo desarrollaremos más que todo en lo referente a lo textual porque nos interesa observar cómo los recordatorios como textos construyen esa identidad a través de breves narraciones biográficas. Hemos decidido comenzar por el análisis de los recordatorios como práctica discursiva, seguir con el análisis de estos como texto y concluir con el análisis de estos como práctica social, pero teniendo en cuenta que esta tripartición es sólo con fines analíticos, ya que las tres dimensiones están interrelacionadas.

\section{ANTECEDENTES HISTÓRICOS Y CONTEXTO DEL PRIMER RECORDATORIO}

El 24 de marzo de 1976 se produjo en Argentina el golpe de estado más brutal de todos los ocurridos durante el siglo XX en este país. Si bien todos los gobiernos de facto anteriores fueron autoritarios y violentos, teniendo en su haber muchos muertos; nunca se había organizado un aparato represivo tan sistemático y abarcador como en la última dictadura. En esta se montó, en todo el país, un plan de persecución y secuestro de militantes y opositores, que en la mayoría de los casos estuvieron cautivos en condiciones infrahumanas en distintos centros clandestinos de detención, y muchos de ellos aún continúan desaparecidos.

En los primeros días o semanas de su desaparición, los familiares confundidos, sin experiencia, y desconociendo la magnitud del aparato represivo, fueron a buscarlos a comisarías y hospitales sin obtener respuesta. Recién casi un año después del golpe empezaron algunas madres a reunirse en la Plaza de Mayo, frente a la Casa de Gobierno, para pedir la "Aparición con vida”. Era el inicio de la agrupación que se llamó Madres de Plaza de Mayo $^{2}$.

Al principio demandaban saber dónde estaban sus hijos, si estaban presos o si habían sido asesinados. Sin embargo, la consigna

${ }^{2}$ Hubo también varias agrupaciones defensoras de los derechos humanos, donde se congregaron los familiares en esos años iniciales de la dictadura, que más adelante se detallan. 
“Aparición con vida”, se fue diluyendo con los años, se remplazó por el pedido de justicia, al asumir muchos familiares que no volverían, que los habían matado y hecho desaparecer a todos. Pero hasta el año 1983, cuando terminó la dictadura, y asumió el presidente elegido democráticamente, muchos padres y madres tenían la esperanza de que aún estaban vivos e iban a ser liberados.

Sin embargo, transcurrido el tiempo, hoy en día existen personas que aún no reconocen la muerte de sus seres queridos por no tener el cuerpo. Panizzo (2012) realizó entrevistas a familiares que afirmaron que no pudieron hacer el duelo hasta recibir los restos identificados, varios años después de la desaparición. Igualmente, a varios les costaba asumir que esos huesos "eran” su pariente. La detención sin proceso judicial, la tortura, el asesinato de opositores y disidentes son prácticas ilegales, contrarias a la constitución y a los derechos humanos. No obstante la desaparición, además de tener todas esas características, resultó aún más cruel y perversa porque significó, durante muchos años para los familiares, la falta de certeza de la muerte del desaparecido. Esta incertidumbre se refleja en algunas de las características de los recordatorios que expondremos..

El 15 de diciembre de 1983, ni bien asumió Raúl Alfonsín, presidente elegido democráticamente, , se formó la CONADEP (Comisión Nacional sobre la Desaparición de Personas), un órgano constituido por personalidades de la cultura, la ciencia, y representantes de las distintas religiones, así como del parlamento nacional (varios de ellos con militancia en los derechos humanos), y que tenía como objetivo no juzgar, sino investigar los crímenes cometidos por el terrorismo de estado en la recientemente terminada dictadura. Se proponía saber qué había pasado con los desaparecidos, y dónde estuvieron cautivos. Durante 280 días los miembros de la CONADEP recibieron miles de declaraciones de familiares de los desaparecidos y sobrevivientes, y trató de localizar los centros clandestinos de detención. El informe final de la Conadep, denominado "Nunca más" es una descripción detallada, que prueba que existió un plan sistemático de exterminio llevado a cabo por el gobierno dictatorial.

En 1985 se realizó el Juicio a las Juntas Militares de la dictadura (nueve militares), que habían cometido graves violaciones a los derechos humanos: dos militares fueron condenados a reclusión perpetua (Videla y Massera), otros tres fueron condenados a distinta cantidad de años de prisión y cuatro fueron absueltos.

En diciembre de 1986 el presidente Alfonsín promulgó la "Ley de punto final", que fijaba "el fin de los juicios [a los mandos militares intermedios involucrados en las violaciones a los derechos humanos en la última dictadura] a todos aquellos que no fueron llamados a declarar antes de los sesenta días corridos a partir de la fecha de promulgación de la presente ley" (D'ALESIO, 2018). El 8 de junio de 1987, se supone como parte de un pacto para que los militares depongan un levantamiento, Alfonsín firmó la "Ley de obediencia debida”, que absolvía de responsabilidad en el terrorismo de estado a los militares que tenían grado inferior a coronel, en virtud de que se afirmaba "que obedecían órdenes". Ambas leyes, junto con los indultos dictados por el presidente siguiente, Carlos Menem (1989 a 1999), son conocidas como “Leyes de impunidad”. En el año 2003, durante la presidencia de Néstor Kirchner, el congreso votó la nulidad de las "Leyes de impunidad", lo que permitió reactivar muchos juicios por crímenes de lesa humanidad, cometidos durante la última dictadura, y encarcelar a muchos represores, no sólo a los altos mandos militares.

\section{LOS RECORDATORIOS COMO PRÁCTICA DISCURSIVA}

Analizaremos, siguiendo las propuestas de Fairclough (referidas en MEURER, 2005), la producción, distribución y consumo de este género del discurso, centrándonos en el corpus.

El periódico Página 12 comenzó a publicarse en mayo 1987 y en agosto de 1988, ya pasados cinco años de la vuelta a una democracia, amenazada y frágil, se publicó sin costo alguno, el primer recordatorio de un desaparecido, firmado por Estela de Carlotto. Ella fue seguida por una gran cantidad de familiares, que, durante más de treinta años, generalmente en todos los aniversarios de la desaparición de sus parientes, publicaban un recordatorio ¿A quién están y estaban destinados los recordatorios? Esta pregunta reúne de alguna manera las distintas dimensiones de análisis propuestas por Fairclough (1992). En el análisis de la dimensión textual veremos que predominan en los recordatorios de Laura Carlotto la apelación directa a ella, pero la podemos pensar como una forma simbólica de comunicación, no es la destinataria real, dado que ya había sido secuestrada y asesinada. 
El propósito de los recordatorios es rendir homenaje a las víctimas del terrorismo de estado y pedir justicia, pero también creemos que se busca interpelar, a través de los lectores del diario, a toda la sociedad, dar a conocer lo ocurrido (que por esos años iniciales de publicación se empezaba a conocer), y que la sociedad se una al reclamo de justicia. De alguna manera los recordatorios permiten que "reaparezcan" simbólicamente los desaparecidos en la sociedad, que lo ocurrido esté presente socialmente a través de este género discursivo, y así, como de otros "géneros de la memoria", que después se enumerarán. Y en consecuencia, que a partir de eso se pueda llegar a encontrar a los hijos de los desaparecidos nacidos en cautiverio y/o apropiados, que en definitiva son desaparecidos que aún están vivos e ignorando su verdadera historia e identidad, como ocurrió en el caso del nieto de Estela de Carlotto,

El periódico Página 12 puede ser caracterizado como de centroizquierda o progresista, con bastante afinidad con los gobiernos kirchneristas. Es decir, fue crítico de las leyes de impunidad y de las políticas neoliberales. Estuvo dirigido por varios famosos periodistas de izquierda, siendo el último de ellos un dirigente de los organismos de Derechos Humanos. Actualmente, es propietario del periódico la Fundación Octubre, que es una empresa de multimedios, que tiene, además, revistas y una radio, y es dirigida por el sindicalista kirchnerista Víctor Santamarina, que hace veinte años creó esta fundación con objetivos de capacitación y culturales.

El diario siempre se caracterizó por su periodismo de investigación, por las denuncias y críticas, sobre todo de los gobiernos de derecha o centro derecha. El estilo del diario preveía desde el comienzo un lector informado, politizado y culto, obviamente con una postura progresista: en general las notas tienen más desarrollo y profundidad que las de los otros diarios; los titulares, tanto de la portada como del interior presentan en general intertextualidad, con referencias, muchas veces irónicas, a textos literarios, películas o refranes. Los estudios de mercado ${ }^{3}$ avalan estas afirmaciones al sostener que: "El 58 por ciento de ellos [los lectores] tiene entre 18 y 52 años y pertenecen al nivel socioeconómico Medio y Medio Alto: AB y C1/C2”.

En Van Dembroucke (2010, p. 39), se realiza una entrevista a Estela Barnes de Carlotto en el año 2005, donde afirma que, el día anterior al décimo aniversario del asesinato de su hija, "sintió la necesidad de hacer algo". Esto confirma el principio del Análisis Crítico del Discurso (ACD), que sostiene que los individuos realizan acciones a través del lenguaje (MEURER, 2005, p. 87). Es decir, ella tuvo la iniciativa de publicar el primer recordatorio, y eligió un diario relativamente nuevo, que no había colaborado con la dictadura, como Clarín y La Nación ${ }^{4}$.

En el nombrado texto de Van Dembroucke (2010, p. 44) se afirma que, en el año 1988, veinte familias siguieron a la Presidenta de "Abuelas de Plaza de Mayo" y publicaron sus recordatorios. A partir del año siguiente, se hizo bastante masivo entre los familiares de desaparecidos, tanto que tuvieron que destinar un empleado para que se ocupe de ellos. De todas maneras, las integrantes de la asociación "Madres de Plaza de Mayo" (liderada por Hebe de Bonafini), decidieron no publicar recordatorios, los denominaron "anuncios muertos" y afirmaron que los recordatorios significaban no solo reducir su lucha colectiva a un nivel personal, sino también admitir públicamente que los desaparecidos estaban, de hecho, muertos, circunstancia que parte de los familiares se niega admitir. $^{5}$

El periódico, es un hipergénero, es decir, un agrupamiento de géneros para componer una unidad mayor (BONINI, 2011, p. 691). Los géneros que lo componen son: noticias, artículos de opinión, entrevistas, críticas de cine y libros, historietas, y recordatorios, entre muchos otros. Sin embargo lo peculiar de estos últimos, es que no son producidos por los periodistas que trabajan para el

\footnotetext{
${ }^{3}$ Citado en la página web del diario,
}

${ }^{4}$ La presidenta de "Abuelas de Plaza de Mayo", Estela de Carlotto me confirmó en una entrevista (MAZUR GEINSES, 2019) que hubo un antecedente de la publicación del primer recordatorio en Pagina 12: ella publicó algunos recordatorios en el efímero diario La Voz, a fines de los '80 durante un breve tiempo. No recuerda fechas, ni cantidad de recordatorios publicados, pero ella misma afirma que no fue consecuente con esa publicación, como después lo fue con la del diario Página 12

${ }^{5}$ En 1986, hubo una escisión de la agrupación "Madres de Plaza de Mayo" debido a discrepancias: en torno a la política de derechos humanos del gobierno de Alfonsín, a la concurrencia o no a testimoniar frente a la cuestionada Comisión Nacional sobre la Desaparición de Personas, y la aceptación de la reparación monetaria que ofrecía el gobierno, entre otras cuestiones y se formó otra organización, llamada "Madres de Plaza de Mayo, Línea Fundadora”, cuyos miembros sí publicaron recordatorios. 
diario, sino que los que los elaboran y mandan a publicar son familiares, o a veces, amigos, de los desaparecidos (con la modalidad similar a los avisos pagos, aunque en este caso no tiene costo alguno). Esto, veremos en relación con la práctica social, implica una identidad diferencial en la producción.

Fairclough (1992 apud MEURER, 2005, p.81) define el género como:

\begin{abstract}
Un conjunto de convenciones relativamente estables y que están asociadas con, y parcialmente realizan, un tipo de actividad socialmente aprobada, como una conversación informal, una compra de productos en una tienda, una entrevista de empleo, un documental televisivo, un poema o un artículo científico." y agrega: "Un género implica no solamente un tipo particular de texto sino también procesos particulares de producción, distribución y consumo de textos.
\end{abstract}

Además de la edición impresa en papel, el diario Página 12 desde el año 2000 tiene una edición digital, es decir, que sale en dos soportes. Esto es importante en relación con la distribución y acceso, en función de que cada vez más vastos sectores de la población, sobre todo juveniles, pero también de otras edades, leen sólo la edición web. De todas maneras, hay que resaltar que los recordatorios sólo salieron en la edición impresa en papel hasta agosto de 2018, a partir de ese momento también están disponibles en la web.

Los recordatorios se publican en cada aniversario de la desaparición, pero específicamente, Estela de Carlotto decidió dejar de publicarlos en 2014, escribiendo una especie de despedida en ese último recordatorio. Veinte días antes, había conocido a su nieto, que vivía bajo el nombre de Ignacio Hurban, y que, por dudas sobre su identidad, se había presentado en la asociación "Abuelas de Plaza de Mayo" y realizado un análisis de ADN, a partir del cual había recibido la confirmación de que era el hijo, nacido en cautiverio, de Laura Carlotto y de Walmir Oscar Montoya ${ }^{6}$.

En ese último recordatorio, R. 2014, ${ }^{7}$ se sostiene: “[...] Pero la vida nos ha premiado con su encuentro y el 5 de agosto pudimos abrazarlo. Quiero entonces, hija recordarte viva. Tendré que despedirme de estos recordatorios. Este será el último porque estás viva en Guido, hoy estás con nosotros porque regresaste en él [...]”. Con esta afirmación corrobora nuestra hipótesis acerca de que los recordatorios, más allá de la ambivalencia que implica la desaparición forzada, se relacionan en parte con los géneros asociados a la muerte. Laura, está simbólicamente viva en su hijo recuperado, por lo tanto, los recordatorios pierden su razón de ser. El hallazgo del nieto de Estela de Carlotto ${ }^{8}$, buscado por treinta y seis años, significó un cierre, en cierto sentido feliz, para esa historia trágica, y por eso se decidió dejar de publicarlos.

En otras circunstancias, ante el hallazgo de huesos y su posterior identificación por el Equipo de Antropología Forense, como perteneciente a un desaparecido, algunas familias también decidieron dejar de publicarlos ${ }^{9}$. Actualmente, se observa una menor cantidad de recordatorios de desaparecidos publicados debido a estos factores, presumimos que sumados a que en algunos casos las madres o padres de los desaparecidos murieron, sin dejar otra familia. También, con la aparición y masividad de las redes, algunas familias optaron por realizar su homenaje a través de blogs y otros sitios web.

No obstante, otra vez surge la ambigüedad asociada con este género, y relacionada con la duda que implica la desaparición, ya que

\footnotetext{
${ }^{6}$ En el último recordatorio se lo describe como el esposo de Laura, cuando estrictamente hasta la aparición de su hijo y su análisis de ADN nadie tenía datos sobre esta relación. No sabemos si en la clandestinidad tuvieron un encuentro ocasional o forjaron una relación estable, de todas maneras, en el último recordatorio se insiste: "Amaste y fuiste amada y por amor concebiste a tu hijo Guido, dentro de tu proyecto de vida junto a Walmir [...]" .
}

${ }^{7}$ En el anexo se presentan tres de los veintisiete recordatorios publicados por Estela de Carlotto, que se identifican como: R. (Recordatorio) y el año de la publicación. Se puede encontrar los recordatorios en en las Referencias( Un espacio de la Memoría (2014) el siguiente enlace (citado): https://www.paginal2.com.ar/diario/elpais/1-252667-2014-08-10.html

${ }^{8}$ Él prefiere que lo llamen con el nombre que le pusieron sus padres adoptivos y con sus apellidos originales: Ignacio Montoya Carlotto. En adelante al citar los recordatorios mantendremos el nombre que aparece en ellos, Guido, pero cuando nos referiremos a él lo llamaremos: Ignacio (Guido).

${ }^{9}$ El hermano del desaparecido Yves Domergue, cuyos huesos fueron hallados e identificados en 2010, me confirmó en un intercambio de mails que tuvimos, que dejó de publicar los recordatorios en 2012. 
se presume que están muertos, pero más allá de lo peculiar del caso de Laura Carlotto, (que más adelante se detalla) no hay cuerpo ni tumba. Parece ser que estas conclusiones o cierres: el hallazgo del hijo un desaparecido nacido en cautiverio o la identificación de los huesos de un desaparecido son como un punto final para esas búsquedas. Esto es lo que diferencia a los recordatorios de los epitafios, mientras estos últimos son permanentes, los recordatorios tienen una publicación periódica (generalmente se publican en los aniversarios de la desaparición) y a veces, ante los mencionados hechos los recordatorios dejan de publicarse. Asimismo, la posibilidad de dejar de publicarse vincula a los recordatorios con los avisos de búsqueda de personas perdidas o desaparecidas, fuera del marco del terrorismo de estado.

Por otro lado, la intertextualidad e interdiscursividad la trataremos en relación con las características textuales.

\section{LOS RECORDATORIOS COMO TEXTO}

En esta dimensión "Fairclough (1992) privilegia la descripción del léxico, las opciones gramaticales, la cohesión y la estructura del texto... [y] enfatiza en las implicaciones ideológicas, a las que él llama "relexicalización” (MEURER, 2005, p. 95)

El recordatorio de los desaparecidos es un género que surge en Argentina, hacia fines de la década del '80 del siglo pasado, interrelacionado con tres sistemas de géneros, "que pueden ser vistos como elementos de una secuencia de prácticas y acciones sociales" (BONINI, 2011, p .693), que se enumeran a continuación:

1) los relacionados tradicionalmente con la muerte (epitafios, discursos de homenaje en los funerales, avisos fúnebres, artículos necrológicos, recordatorios en los aniversarios del fallecimiento de una persona, fuera del terrorismo de estado);

2) los que denominamos "géneros de la memoria", que surgen como una necesidad social de recordar y rendir homenaje a los desaparecidos, gestionados por sobrevivientes, familiares y amigos de desaparecidos durante la última dictadura, así como distintas asociaciones de derechos humanos. Entre los muchos "géneros de la memoria" que podemos mencionar, los más importantes, además de los recordatorios son: las páginas web o blogs dedicadas a un desaparecido, el Archivo Biográfico Familiar de "Abuelas de Plaza de Mayo" ${ }^{10}$, las "Baldosas por la Memoria", ubicadas en distintos puntos de la ciudad de Buenos Aires y de otras ciudades del país, que señalan donde vivieron o estudiaron los desaparecidos y el Monumento a las Víctimas del Terrorismo de Estado del Parque Nacional de la Memoria. Este último está compuesto por una lista de las víctimas ${ }^{11}$ que se podrían asimilar a una serie de miles de epitafios en un soporte de mármol, pero sin cuerpos;

3) el tercer género, más acotado, se relaciona con los avisos o anuncios de búsqueda de personas desaparecidas fuera del contexto dictatorial, ya sea el caso de personas extraviadas, objeto de delitos, o que ellos mismos hayan cometido delitos.

Es decir, que tanto los que llamamos "géneros de la memoria", como otros géneros tradicionalmente relacionados con la circunstancia de la muerte, junto con los de búsqueda de paradero, constituyen tres sistemas de géneros, que confluyen en parte en los recordatorios de los desaparecidos, conforme explica Bazerman (1994 apud BONINI, 2011, p. 693) "[...] en un sistema ordenado secuencialmente, un género crea condiciones para la existencia de otro”. El recordatorio, como género híbrido, justamente al presentarse la desaparición en el contexto del terrorismo de estado como un hecho que genera incertidumbre, en los familiares está en un punto de intersección entre estos tres sistemas de géneros. Al ir enumerando las características del recordatorio, estableceremos semejanzas y diferencias con los géneros mencionados.

\footnotetext{
${ }^{10}$ Archivo preparado por “Abuelas de Plaza de Mayo” y colaboradores con datos biográficos, narraciones de familiares y amigos, fotos, biogramas, etc., con el objetivo de entregarle, a los niños apropiados, hoy adultos, para que cuando recuperen su identidad conozcan la historia de sus padres desaparecidos y sus familias.

${ }^{11}$ Donde consta el nombre, apellido, edad, el año de desaparición y eventualmente algún dato, por ejemplo: en el caso de Laura Carlotto, dice "embarazada".
} 
El recordatorio como texto presenta un recuadro de aproximadamente diez centímetros de ancho y ocho de alto ${ }^{12}$, que aparece en las páginas de noticias nacionales del diario Página 12. Tiene un encabezamiento, una parte central o "cuerpo" del recordatorio, y suele tener una o varias firmas. A veces antes o después de estas hay una frase de cierre.

El encabezamiento es muy similar a los epitafios, un género discursivo que aparece en las lápidas de las tumbas, aunque presenta algunas diferencias. Como en los epitafios aparece la foto ${ }^{13}$, el nombre y el apellido. Mientras en los epitafios aparece la fecha de nacimiento y de muerte, como delimitando la vida, en los recordatorios de Laura Carlotto (y es similar lo que presentan los de otros desaparecidos) aparecen fechas, pero a veces van fluctuando en las distintas publicaciones. En particular, en los recordatorios de Laura Carlotto, esto se debe a que ella fue secuestrada cuando estaba en la clandestinidad, estuvo cautiva durante, aproximadamente, nueve meses en un centro clandestino de detención y fue asesinada por las fuerzas represivas. Sus padres fueron notificados y concurrieron a una comisaría donde fueron citados. Allí les comunicaron su muerte en un "enfrentamiento", y reconocieron el cuerpo, que les fue entregado. Se trata de uno de los pocos casos en que el cuerpo de un desaparecido fue devuelto a sus familiares durante la dictadura ${ }^{14}$. Por eso en sus recordatorios, sobre todo los de los primeros años de publicación, se observa una oscilación entre su fecha de desaparición o secuestro, entre la fecha del asesinato (en que les entregaron el cuerpo), la fecha que según versiones de los sobrevivientes nació el nieto de Carlotto, incluso en algunos, aparece la fecha de la publicación, y a veces presentan varias o todas estas fechas.

Esas oscilaciones, que relacionan íntimamente el recordatorio como texto y como práctica social se basan en la ambigüedad, ya mencionada, que implica la desaparición, especialmente para los familiares, aunque también socialmente. Habiendo pasado tantos años, no sólo ahora, sino desde la publicación de los primeros recordatorios, ¿que esté desaparecido significa que esté muerto? Si no hay cuerpo, ni ceremonias o rituales fúnebres, ¿se puede reconocer que murió? Si se hallan restos de una persona desaparecida que son identificados por el equipo de Antropología Forense por ese solo hecho, ¿el que era desaparecido deja de serlo para ser denominado "asesinado"? O en el caso en el que nos centramos: una persona que estuvo desaparecida por varios meses, si su cuerpo se lo entregan a sus familiares después de ser asesinada, ¿deja de ser identificada como desaparecida? Estas y otras preguntas, profundas, existenciales se hicieron los familiares y los organismos de derechos humanos, y los fueron respondiendo de diversas maneras, en la medida que lo iban elaborando, procesando mentalmente.

Aunque hay distintas posturas al respecto, en este caso, y en otros donde, en general, después de muchos años se lograron identificar los huesos, creemos que las víctimas no pierden la característica de desaparecidos por esta aparición de sus restos, más que todo porque estuvieron desaparecidos y fueron asesinados en ese contexto. De todas maneras, la identidad social del desaparecido se fue construyendo con el tiempo, pues, en el primer recordatorio escrito por Estela de Carlotto para su hija Laura (R. 1988), debajo del nombre y el apellido dice: "A diez años de su asesinato por la dictadura militar". Y a al año siguiente, en R. 1989, aparece la fecha del asesinato y dice: "A 11 años del asesinato de Laura Carlotto". Y más abajo, aparecen entre paréntesis los adjetivos calificativos: "(Detenida-desaparecida embarazada)". Es decir, recién se asume, en este segundo recordatorio, esas condiciones, de todas maneras no en todos los recordatorios siguientes vuelve a aparecer la palabra compuesta detenida-desaparecida. Esta palabra implica que no es cualquier desaparición, sino una en el marco de una detención y secuestro realizado en el contexto del terrorismo de estado, aunque a veces se usa sólo la palabra "desaparecida". En R. 1990, debajo del nombre dice: "Desaparecida el 20-11-77/ Asesinada el

\footnotetext{
${ }^{12}$ Estos parámetros fueron fijados por el diario con el tiempo, los primeros recordatorios pueden presentar distintas medidas.

${ }^{13}$ En los recordatorios de algunos desaparecidos no aparecen fotos. Los recordatorios de Laura Carlotto, R. 1999 y R. 2003 , tampoco tienen foto.
}

${ }^{14}$ En la entrevista que le hice (MAZUR GEINSES, abril 2019), Estela de Carlotto refiere que fue a ver a uno de los altos mandos del ejército, el general Bignone, al que pudo acceder por haber sido compañera de trabajo de su hermana, y al cual le pidió por su hija, Laura. "No la maten”, le dijo. "Si cometió un delito para ustedes, júzguenla”. Bignone le respondió que los iban a matar a todos, que no querían que pase como con los Tupamaros en Uruguay, que se fortalecían en las cárceles. Ante esto Estela de Carlotto pensó que su hija ya estaba muerta y le pidió que por lo menos le entreguen el cuerpo. A este pedido le atribuye Estela de Carlotto que le hayan entregado el cuerpo y que hayan simulado un enfrentamiento. 
25/08/78”. En R. 1991, debajo del nombre, “Secuestrada el 26 de noviembre de $1977^{15}$. Embarazada. Su bebé Guido nació el 26 de junio de 1978. En Cautiverio. Asesinada el 25 de agosto de 1978”.

No vamos a extendernos más porque los otros recordatorios, aunque con variantes, construyen, en el encabezamiento, su identidad de forma similar a estos tres últimos mencionados. Como si en el primero no se hubiese asumido, tal vez por el hecho de que les entregaron el cuerpo, ella también era una detenida-desaparecida, que lo sería siempre.

Las frases finales son otro rasgo que vincula este género a ciertos epitafios, que poseen una frase o dedicatoria e incluso a veces la firma de familiares del fallecido. Analizaremos las características de estas frases finales más adelante.

También podemos ver similitudes con los avisos fúnebres publicados en los diarios, especialmente por la aparición del nombre y la circunstancia o datos de la muerte. Aunque los avisos fúnebres son muy breves y tienen como objetivo dar a conocer la muerte de una persona y dónde serán velados o enterrados sus restos. Además, suelen presentar un símbolo religioso, como la cruz o la estrella de David, al igual que muchos epitafios, elementos que no aparecen en los recordatorios de los desaparecidos. Otra cuestión que resulta significativa es que el diario Página 12 no tiene, ni nunca tuvo, una sección dedicada a los avisos fúnebres comunes (como sí tienen los diarios Clarín y la Nación), pero es el único donde aparecen los recordatorios de los desaparecidos de la última dictadura. Por otro lado, los avisos fúnebres se encuentran en las últimas páginas de esos diarios en una sección aparte, mientras que los recordatorios de los desaparecidos se encuentran en el diario Página 12 en páginas centrales.

Si bien actualmente, en los diarios Clarín y La Nación, se publican menos avisos fúnebres que en otra época debido a que se comunica el fallecimiento en las redes sociales, también aparecen, en el mismo formato de avisos fúnebres, algunos recordatorios por el aniversario de la muerte de personas que murieron en circunstancias ajenas al terrorismo de estado. Estos son más breves, algunos apelan directamente al fallecido, pero la gran diferencia con los recordatorios de los desaparecidos es que no presentan ni una síntesis biográfica apologética, ni pedidos de justicia, ni referencias al contexto de la publicación, como encontramos en ellos.

Además, los recordatorios de los desaparecidos se emparentan con los avisos de búsqueda de paradero, publicados por las familias y/o la policía para la búsqueda de personas, pero fuera del marco de una dictadura. Estos dan datos para la identificación de la persona con vida (vestimenta, datos físicos), en cambio, en los recordatorios (más allá de las diferentes posturas sobre el tema), los familiares parecen haber asumido, si no la muerte, la desaparición ${ }^{16}$. A pesar de eso, hay algunos recordatorios que piden datos sobre el cautiverio del desaparecido, como un deseo de reconstruir la historia, se apela a los que tengan información sobre esas cuestiones para que se comuniquen con los familiares.

La identidad de Laura Carlotto también se va construyendo en el "cuerpo" o parte central del texto, donde en la mayoría de los recordatorios se narran circunstancias biográficas, generalmente con verbos en pretérito, centrándose en elogiar su lucha, muchas veces apelando directamente a Laura, mediante el uso de la segunda persona en verbos y pronombres: Por ejemplo: en R.1989: "Te quitaron la vida por luchar por un país mejor, queriendo así borrar tu presente. Te quitaron a tu niño nacido en cautiverio, para borrar tu futuro [...]". En R. 2000: "Cada día crece tu presencia en tu ausencia. Vives junto a nosotros en tus convicciones y compromiso por conseguir un país sin desamparo con justicia e igualdad para todos". En R. 2014: "Creciste y viviste como apurada, querías modificar el destino de tu Patria. Luchar por la justicia social fue tu lema [...]”.

La voz de Laura, como recurso polifónico e intertextual aparece en la parte central de varios recordatorios, a través de la cita de cartas, que ella escribió a su familia desde la clandestinidad, antes de ser secuestrada. Por ejemplo: en R 1999, Laura, en una carta, apela a su mamá: "Tené presente que toda la lucha que llevamos adelante los Montoneros es dura muchas veces, pero a la vez hermosa, ya que peleamos por amor, por amor al pueblo, a la justicia y la libertad”. A través de esas cartas también se construye la

\footnotetext{
${ }^{15}$ Estela de Carlotto, en la entrevista (MAZUR GEINSES, 2019), afirmó que la fecha del secuestro o desaparición (26/11/77) es una estimación, ya que Laura estaba en la clandestinidad. De todas maneras, le atribuye a un error tipográfico del diario la fecha del 20/11/77, que solo aparece en el tercer recordatorio, R. 1990 (el primero en que se fija una fecha de desaparición o secuestro).
}

${ }^{16}$ Recordemos que los recordatorios se empiezan a publicar diez o más años después de la desaparición, según los casos. 
identidad de Laura como una luchadora por la liberación del pueblo, y en este recordatorio, por primera vez se asume que ella pertenecía a la organización Montoneros, que participó en la lucha armada, y fue demonizada, especialmente a partir del golpe de estado $^{17}$. En R. 2009, cita otra vez a su hija desaparecida: "Nadie quiere morir. Todos tenemos un proyecto de vida. Pero miles de nosotros moriremos y nuestra muerte no será en vano”. En este texto se agrega la dimensión de mártir. Esta frase también es citada en R. 2011.

El otro recurso polifónico que aparece es la cita de un sobreviviente que habló con Estela de Carlotto: En R. 1995: "A esta hora la sacaron del campo -me dijo recordando hoy Luis, un sobreviviente - A mí me dio el último beso [...]”.

La intertextualidad también se manifiesta en la parte central de algunos recordatorios con la cita de textos literarios, que por su estilo grandilocuente y hasta religioso o profético rompen con la isotopía estilística de los recordatorios de otros desaparecidos ${ }^{18}$ : Por ejemplo: en R. 1989: "A qué pueblo bueno habéis emborrachado de sangre...!! Qué venganza estáis fraguando [...]”19. En R. 1990: "Llegan con la aurora, a Laura/los pulpos de colmillos grandes [...]"20. En R. 1996: "La sombra de Caín un día regresará carnicero [...]"21. Estas citas contrastan con las de recordatorios de otros desaparecidos, que suelen citar a escritores de izquierda, como Galeano y Benedetti, entre otros y que tienen un estilo más llano y directo.

Lo dicho hasta aquí sobre la parte central del texto guarda, en cierto sentido, similitudes con dos géneros discursivos relacionados tradicionalmente con la muerte: discursos de homenaje en los funerales ${ }^{22}$ y artículos necrológicos que aparecen en los periódicos cuando muere alguna personalidad conocida. En ellos se realiza un panegírico de la persona muerta, a veces pueden presentar intertextualidad, incluyendo frases dichas o escritas por el fallecido o anécdotas. En cambio, en los recordatorios de los que nos ocupamos, en la síntesis biográfica ocupa un lugar central la identidad social de desaparecido y las características de esa desaparición. Es decir, la biografía incluye, y en los de Laura cada vez se va acentuando más en la medida en que se nota en los recordatorios, una toma de posición política (o al menos su explicitación), la apología de su lucha, correlativa con la denuncia de represores y el pedido de justicia, así como alusiones al contexto social de la publicación.

En R. 1988 se denuncia: “A diez años de su asesinato por la dictadura militar". En R. 1991: "Laura permaneció 9 meses secuestrada en el campo de concentración 'la Cacha' de la Plata, Área Operacional 113. / Responsables ${ }^{23}$ : Ejército, Marina, Policía de la Pcia. de Bs. As. Laura tuvo su hijo en el Hospital Militar./ Responsables: Ejército. Laura fue asesinada en La Matanza, Pcia. de Bs. As. Área Operacional 114 /Responsables: Ejército, Policía de la Pcia. de Bs. As. [...]”. Y finaliza: "Todos ellos son responsables del secuestro y muerte de Laura y ellos deberán responder sobre su hijito Guido”.

En los recordatorios, al narrar y denunciar el secuestro, tortura, desaparición y muerte de Laura, así como el nacimiento en cautiverio de su hijo y su apropiación, se identifican otros actores sociales, que son los represores. Si bien en el segundo recordatorio (R. 1989) aparece un sujeto tácito: “Te quitaron la vida [...]”, en la mayoría se los denuncia como colectivo: en R. 1991, recién citado, donde se dan bastantes precisiones, en R. 1988 se refiere en general a la "dictadura militar", en R. 2002 "dictadura militar genocida”, en R. 2012 y R. 2013 “dictadura cívico- militar", en R. 2006 “los asesinos”, en R. 2008 “los genocidas".

En varios recordatorios se pide justicia: en R. 1991, “Año tras años estas fechas son recordadas y denunciadas por quienes buscamos: Verdad, Justicia y un nieto robado [...]”; en R. 1992, "No dejaremos de reclamar justicia hasta que esta incline su balanza contra los

\footnotetext{
${ }^{17}$ Varios sectores de izquierda realizaron también críticas a Montoneros por cuestiones estratégicas, éticas y políticas.

${ }^{18}$ Estela de Carlotto, en una entrevista (MAZUR GEINSES, 2019), reconoce su formación religiosa y se asume como católica. Afirma que cuando mataron a Laura "se enojó con Dios", pero asevera que para enojarse con Dios hay que creer en él.

${ }^{19}$ No está aclarado en el recordatorio, pero pude averiguar que se trata de una poesía escrita por el cuñado de Laura.

${ }^{20}$ Firmado por "Noel, Santiago de Cuba".

${ }^{21}$ Se aclara en el recordatorio: "Illegal rap. Escrito en Cerdeña, Italia”.

${ }^{22}$ No es un género usual en Argentina.

${ }^{23}$ En negrita en el recordatorio.
} 
asesinos con quienes nos obligan a convivir. Y esa Justicia debe alcanzar para que tu hijito Guido, al igual que centenares de pequeñas víctimas de la dictadura, deje de ser cautivo del siniestro proyecto que lo secuestró"; en R. 2008: "Qué puede reparar en algo semejante crimen sino la Verdad y la Justicia que implacablemente debe condenarlos".

En diversos recordatorios hay referencias al contexto social y político del momento de la publicación. En R. 1989: "Esos mismos que hoy quieren borrar su pasado de su accionar de secuestros, torturas y muertes" (en referencia a las leyes de Impunidad). En R. 2001: "Cuanta falta nos hace tu presencia y la de tus compañeros de militancia en estos tiempos en que se cumplen inexorablemente los pronósticos de injusticia social” (en plena crisis política y económica, que llevó a la caída de un gobierno neoliberal). En R. 2003: "Un viento de esperanza despierta en nuestra tierra para dar paso a tus ideales. Un nuevo sol alumbra a los que sobrevivieron para no olvidar las palabras VERDAD Y JUSTICIA ${ }^{24}$ [...]" (la esperanza se relaciona con las políticas de derechos humanos implementadas por Néstor Kirchner). En R. 2010: "los herederos de ella [tu lucha] están reconstruyendo el país soñado para alcanzar aquellos ideales de justicia social” (en el contexto de gobiernos kirchneristas). Incluso en el último recordatorio (R. 2014) se menciona el contexto político del nacimiento de Laura: "Marcó el año de tu nacimiento, 1955, un nuevo y aberrante atentado a la democracia por parte de los civiles y militares apátridas. Bombardeos, fusilamientos, proscripciones”.

La creciente toma de posición política que se observa en los recordatorios se debe a la conciencia que fue adquiriendo Estela de Carlotto al luchar contra las arbitrariedades e injusticias de la dictadura y de los distintos gobiernos neoliberales, así como al reconocer las políticas de memoria, verdad y justicia, y de cierta redistribución de la riqueza del kirchnerismo. También es probable que sus otros tres hijos hayan influido ideológicamente, ya que no sólo trabajaron por los derechos humanos, sino uno fue funcionario y el otro legislador de los gobiernos kirchneristas ${ }^{25}$.

Los firmantes y frases finales a lo largo de los años son variados, a pesar de que Estela de Carlotto sostuvo, en la entrevista que le hice (MAZUR GEINSES, 2019), que ella redactó todos los recordatorios. En R. 1988 firman: "Tus padres, tus hermanos, tu familia, tus amigos y los demás (aunque no lo sepan) no te olvidamos”. En R. 1989 y R. 1991: "Estela Barnes de Carlotto”. En R. 1992 no hay firmantes. En R. 1997: "Estela, Guido ${ }^{26}$ y los tuyos". En R. 1998: "Tus padres, hermanos, tu familia, y tu hijo Guido desde donde esté”. En R.1999 incluye una frase final que da cuenta de su radicalización al referirse intertextualmente a una conocida frase que el Che Guevara le escribió a Fidel Castro ("Hasta la victoria siempre"): "Hasta la victoria ¡LAURA! 27 Tu familia y todos los que no olvidamos”. Otras frases finales, en R. 1994: “Tu ejemplo y el de 30.000 compañeros será sin duda el faro que guíe las banderas por la justicia social. Y tu pequeño Guido que te-nos robaron encontrará que estás viva y lo estás esperando en ellos y nosotros”. En R. 1995: "Esta es la posición inclaudicable de tus padres, Laura, tus hermanos, tu familia y todos aquellos que no ahorran un segundo de sus vidas para que triunfe la verdad".

Si bien, en los recordatorios de Laura, predomina la apelación a ella, esta aparece, a veces, combinada con la función expresiva del lenguaje. En el que más se evidencia es en R. 1993, donde se utiliza la primera persona en verbos y pronombres para hablar del dolor de su familia, con verbos en presente, combinado con el uso de impersonales en la oración, para referirse a Laura: "Se nos desgarra el alma para siempre, como una copa de cristal que se hace añicos, dispersos los pedazos algo nos falta adentro, queda un vacío. Duele el solo pensarla, se extraña su presencia, se la imagina, se la llama, se la clama...”. En este y otros fragmentos se observan distintos recursos retóricos o literarios, en el recién citado, la comparación y la metáfora, en R. 1988, R. 1989 y las anáforas (repeticiones del comienzo de oraciones). En R. 2012 no sólo el lenguaje, si no la composición misma del recordatorio parece poética, con recursos como paralelismos sintácticos: "Sigo tus pasos y tú me acompañas/tus ideales me guían/tu valor me contagia/avanzo contigo en un camino que no tiene retorno".

\footnotetext{
${ }^{24}$ Con mayúsculas en el recordatorio.

${ }^{25}$ Consultada sobre esto en la entrevista (MAZUR GEINSES, 2019) afirmó que también en la historia institucional de la Asociación Abuelas de Plaza de Mayo hubo a lo largo de los años una mayor conciencia política, que "al principio eran muy ingenuas".

${ }^{26}$ Guido, además de ser el nombre que Laura le puso a su hijo nacido en cautiverio, era el nombre de su padre (el esposo de Estela de Carlotto), así como el de uno de sus hermanos.

${ }^{27}$ Con mayúsculas en el recordatorio.
} 
Estableciendo una comparación con los recordatorios de otros desaparecidos se encuentran bastantes similitudes con los que Estela de Carlotto elaboró para su hija. De todas maneras, como es obvio, no hay uniformidad absoluta entre ellos. En los recordatorios de Laura predomina la narración de su historia y la reivindicación de su lucha, a través de la apelación directa a ella. Además encontramos el recurso polifónico de la cita de sus cartas, así como el pedido de justicia y de aparición de su hijo, nacido en cautiverio, Sin embargo en algunos de los recordatorios de otros desaparecidos se observa otras variantes: en unos se destaca la cita de textos literarios, en otros aparece más la función expresiva para dar cuenta de cómo sufren o extrañan al desaparecido los familiares. También hay variantes de extensión y estilísticas. Pero esto no solo varía de familia en familia, sino, como en el caso que nos ocupa, a través del tiempo. Incluso a lo largo de los años empezaron a aparecer recordatorios colectivos, especialmente para compañeros de trabajo o estudio, que fueron secuestrados, o personas que compartieron el cautiverio. También se comenzó a ver más alusiones al contexto social y político de la publicación, así como la convocatoria a distintos homenajes a través de los recordatorios, por ejemplo: la colocación de una "baldosa por la memoria" en el lugar donde vivió, estudio, trabajó o fue secuestrada una persona.

\section{LOS RECORDATORIOS COMO PRÁCTICA SOCIAL}

Conforme a lo afirmado por Meurer (2005, p. 100), "Fairclough procura relacionar los textos con prácticas sociales más amplias, de las cuales el texto es una parte". Se propone examinarlo en términos de ideología y hegemonía, pero también podemos hacerlo a través de las identidades sociales (MEURER, 2000), y del concepto de comunidad discursiva ${ }^{28}$ (SWALES, 2009, p. 7).

Si bien no podemos considerar que los familiares y amigos que publican los recordatorios forman una única comunidad discursiva (SWALES, 2009), se puede afirmar que constituyen una red de comunidades discursivas interconectadas. La inmensa mayoría de los familiares y amigos que los publica pertenece a alguna de las siguientes entidades defensoras de los derechos humanos: "Abuelas de Plaza de Mayo", "Madres de Plaza de Mayo, Línea Fundadora”, "Familiares de Desaparecidos y Detenidos por Motivos Políticos", APDH (“Asamblea Permanente por los Derechos Humanos”) e HIJOS ("Hijos e Hijas por la Identidad y la Justicia contra el Olvido y el Silencio"), entre los principales organismos, aunque hay varios más.

Habría que hacer una investigación sobre el tema, que excede el objetivo de este trabajo, pero se presume por el conocimiento social que se tiene sobre estos organismos, que cada uno de ellos posee las características de una comunidad discursiva, descripta por Swales (2009, p. 7): poseen un conjunto de objetivos perceptibles, tienen mecanismos de intercomunicación entre sus miembros, usan mecanismos de participación para una serie de propósitos, utilizan una selección creciente de géneros en relación con sus objetivos y mecanismos participativos, poseen una terminología específica (en este caso, hay un campo discursivo relacionado con estas entidades de derechos humanos), y por último poseen una estructura jerárquica. Lo que habría que investigar es si las interconexiones entre estas comunidades discursivas son homogéneas y/o sistemáticas. Es público y notorio que algunos miembros de "HIJOS" tienen un fluido y cordial contacto con la asociación "Abuelas de Plaza de Mayo", así como "Abuelas de Plaza de Mayo" tiene una buena relación con "Madres de Plaza de Mayo, Línea Fundadora”. Sin embargo también es manifiesta la distante relación entre "Madres de Plaza de Mayo" y la mayoría de las agrupaciones mencionadas

Cada una de estas agrupaciones presenta una identidad diferencial, la mayoría incluye en su nombre como dato identitario la relación de parentesco que tenían con un desaparecido: "Madres...", "Abuelas...", "HIJOS”, "Familiares", pero, además de esto, cada agrupación ha fijado su postura en relación con diversas cuestiones antes mencionadas, y en algunos casos han tenido intensos debates y hasta rupturas.

Por otro lado, podemos decir que los familiares manifiestan una postura progresista, algunos (como la misma Estela de Carlotto) han contado que, hasta el momento de la desaparición de sus hijos, tenían una postura de derecha o de "centro", pero que al iniciar la búsqueda y advertir las injusticias y arbitrariedades de la dictadura, su postura política cambió totalmente, se volvieron

${ }^{28}$ La comunidad discursiva podría ser tratada también en la dimensión correspondiente a la práctica discursiva, pero preferimos tratarlo en relación con la práctica social. 
cuestionadores del "statu quo" y del gobierno militar, saliendo en muchas ocasiones a pedir por su hijo o hija y poniendo en riesgo su vida (de hecho hay varias mujeres pertenecientes a "Madres de Plaza de Mayo" desaparecidas). Hebe de Bonafini, la presidenta de la mencionada entidad, tiene una frase reveladora: "Nuestros hijos nos parieron". Es decir, ella, Estela de Carlotto y miles de familiares deben su identidad social a esa desaparición y a esa búsqueda.

En nuestro recorte sólo nos vamos a centrar en la identidad de Estela de Carlotto, ya que, si bien los miembros de su familia aparecen como firmantes de muchos de los recordatorios, ella afirma que fue la única redactora. Estela de Carlotto fue maestra, era directora de una escuela y ama de casa, cuando su hija Laura fue secuestrada en noviembre de $1977^{29}$. Desde entonces, su identidad tiene que ver con la desaparición de su hija y con esa búsqueda. Desde el año 1977 la Asociación Abuelas de Plaza de Mayo lucha por la restitución de los niños secuestrados junto a sus padres o nacidos en cautiverio. La mayoría de estos niños (se presume que 400) fueron apartados de sus padres y apropiados por familias de los militares o allegados a ellos. En algunos pocos casos, como el de Ignacio (Guido), el nieto de Carlotto, fueron adoptados, ilegalmente, por familias que desconocían que esos bebés habían nacido en cautiverio y habían sido separados de sus madres, que en la actualidad continúan desaparecidas

Estela de Carlotto ya poseía una identidad y reconocimiento público como defensora de los derechos humanos en 1988, cuando publicó el primer recordatorio. No obstante su figura se ha hecho más importante con el tiempo. En 1983, cuando volvió la democracia, había 12 nietos restituidos. En la década del ' 80 las Abuelas visitaron academias y universidades del exterior para pedir ayuda a científicos, y lograron obtener lo que se llamó el "índice de abuelidad” ya que hasta el momento el análisis de ADN sólo se podía hacer de padres a hijos, y los primeros estaban desaparecidos. Este fue un hallazgo científico impulsado por "Abuelas de Plaza de Mayo", que permite que hoy se haya restituido la identidad a 129 nietos, la última fue a principios de abril de $2019^{30}$. Ya son hombres y mujeres, que deben procesar mentalmente que vivieron bajo una identidad falsa, que no son quienes creían que eran, ni los que creían que eran sus padres son su padres La restitución de cada nuevo nieto implica una conferencia de prensa de la Asociación Abuelas de Plaza de Mayo con la presencia ineludible de Estela de Carlotto, así como otras abuelas miembros, sus nietos ya restituidos y familiares, y se trata de un hecho cubierto por los medios de comunicación, pero la restitución del nieto de Carlotto, en el año 2014, fue un acontecimiento nacional.

La construcción de la identidad social de Laura Carlotto como desaparecida, así como la de los represores, ya fue tratada en relación con las características textuales de los recordatorios.

El hijo de Laura, Ignacio (Guido) Montoya Carlotto fue apropiado desde su nacimiento en cautiverio y vivía con una identidad que no era la suya, Ignacio Hurban. Es decir, era un desaparecido que estaba con vida. Él mismo concurrió a "Abuelas de Plaza de Mayo" para hacerse los exámenes de ADN ante dudas que le habían surgido sobre su identidad. A diferencia de otros niños apropiados nacidos en cautiverio, él no fue llevado por la familia de un militar, sino que el dueño de una estancia en la Provincia de Buenos Aires se lo entregó siendo bebé a una pareja que cuidaba sus campos y que no podía tener hijos. Con ellos él no padeció ni los maltratos ni el "lavado de cerebro" que padecieron otros niños apropiados, que se criaron con militares. Su padre biológico, era un compañero de Laura, que está también desaparecido, Walmir Oscar Montoya, militante montonero nacido en Comodoro Rivadavia, Provincia de Chubut y criado en la localidad de Cañadón Seco, en la provincia de Santa Cruz. Conoció a Laura Carlotto en La Plata, cuando fue a estudiar a la universidad. Por testimonios se sabe que ambos estuvieron cautivos en el centro clandestino de detención "La Cacha”. Lo peculiar es que Estela de Carlotto no sabía que su hija estaba embarazada, ni conocía esa relación cuando su hija desapareció. Por declaraciones de sobrevivientes pudo enterarse del parto, que fue corroborado por el equipo de Antropología Forense por ciertas modificaciones óseas en las caderas que tenían los restos de Laura. Desde ese momento empezó la búsqueda, sin tener certezas de quién era el padre. Con el análisis de ADN, al contrastarlas con las muestras de los Familiares en el Banco Nacional de Datos Genéticos, Ignacio (Guido) pudo descubrir su verdadera identidad, no sólo quien era su madre, sino también su padre. Actualmente, sigue viviendo en la ciudad de Olavarría en la Provincia de Buenos Aires, dando clases de música y

\footnotetext{
${ }^{29}$ En agosto de 1977, su marido, que iba encontrarse con su hija Laura, estuvo veinticinco días desaparecido y fue posteriormente liberado. Desde ese momento, percibiendo que estaba en riesgo, Laura pasó a la clandestinidad.

${ }^{30}$ Cuando estaba escribiendo este artículo, se produjo la restitución de la nieta número 127, cuando lo estaba reescribiendo para su publicación, ya habían restituido la nieta 129. Es probable que hasta el momento de la publicación se produzcan nuevas recuperaciones.
} 
tiene un contacto fluido con su familia materna y paterna de origen, y especialmente con su abuela, Estela de Carlotto.

\section{CONCLUSIÓN}

Los recordatorios de los desaparecidos conforman un género híbrido, con características de varios géneros discursivos. Se encuentran en un punto de intersección entre los géneros discursivos relacionados con la circunstancia de la muerte, los que denominamos "géneros de la memoria" y los que se utilizan para la búsqueda de una persona, fuera del marco de una dictadura. La hibridez del género tiene relación con la ambigüedad, la incertidumbre que implica la desaparición forzada para los familiares, que son los productores de estos textos. Los recordatorios de los desaparecidos son y no son epitafios, son y no son discursos de homenaje en los funerales, son y no son anuncios de búsqueda de paradero. A la vez, a través de los recordatorios como "género de la memoria" los familiares realizan varias acciones con valor social: recuerdan, rinden homenaje a los desaparecidos, piden justicia, y por la aparición de los niños nacidos en cautiverios (hoy adultos), denuncian a los represores, convocan a actividades de homenaje e interpelan a la sociedad sobre estos temas.

\section{REFERENCIAS}

BONINI, A. Mídia / suporte e hipergênero: os gêneros textuais e suas relações. Revista Brasileira de Linguística Aplicada, v. 11, n. 3, p 679-704, 2011.

BONINI, A. Análise crítica de gêneros discursivos no contexto das práticas jornalísticas. In: Seixas, Lia, Pinheiro, Najara Ferrari. (org.), Gêneros: um diálogo entre comunicação e Linguística Aplicada. Florianópolis: Insular, 2013. p 103-120.

D’ ÁLESIO, R. Ley de Punto Final: el camino hacia la impunidad. La izquierda diario. Buenos Aires, 22 feb. 2018. Disponible en: http://www.laizquierdadiario.com/Ley-de-Punto-Final-El-camino-hacia-la-impunidad.

FAIRCLOUGH, N. Discourse and social change. Cambridge: Polity Press, 1992

MAZUR GEINSES, G. Entrevista a Estela de Carlotto, Buenos Aires [sin publicar], abril, 2019.

MEURER, J. L. O trabalho de leitura crítica: recompondo representações, relações e identidades sociais. Ilha do Desterro, Florianópolis, n. 38, p.155-171, 2000..

MEURER, J. L. Gêneros textuais na análise crítica de Fairclough. In: MEURER, J. L.; BONINI, A.; MOTTA-ROTH, D. (org.). Gêneros: teorias, métodos, debates. São Paulo: Parábola Editorial, 2005. p. 81-106

PANIZZO, L. Ausencia y desaparición el caso de los desaparecidos de la última dictadura militar en Argentina. Argos, Caracas, v. 29, n. 57, p 94.-125, 2012. 
SWALES, J. M. Repensando gêneros: uma nova abordagem ao conceito de comunidade discursiva. In: BEZERRA, B. G.; BIASIRODRIGUES, B.; CAVALCANTE, M. C. (org.). Gêneros e sequências textuais. Recife: Edupe, 2009 [1992]. p. 197-220.

UN ESPACIO de memoria. Diario Página 12, Buenos Aires, 10 ago. 2014 . Disponibles en: https://www.pagina12.com.ar/diario/elpais/1-252667-2014-08-10.html.

VAN DEMBROUCKE, C. Absent yet still present: family pictures in Argentina's Recordatorios. Texas: Thesis Presented to the Faculty of the Graduate School of The University of Texas at Austin, 2010.

\section{() (1) $\circledast$}



por la dictadura militar

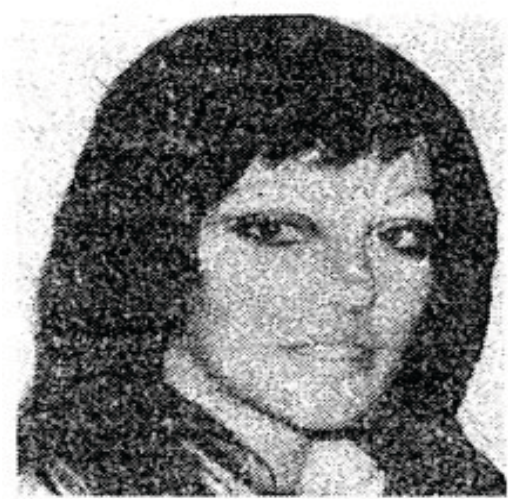

Diez años es demasiado tiempo para no verte. Diez años es demasiado tiempo para que no vivas, amando y sutriendo entre nosotros, envejeciendo como ès la ley de Dios.

Diez años de búsqueda de tu justicia (con memoria para la historia) es demasiado tiempo para no haberla obtenido. Diez años buscando el hijito que. te robaron es demasiado tiempo para que aún no nos acompañe el clamor general en la demanda.

Diez años no son demasiados para seguir tu ejemplo.

Tus padres, tus hermanos, tu familia, tus amigos y los demás (aunque no lo sepan) no te olvidamos.

25-8-88 


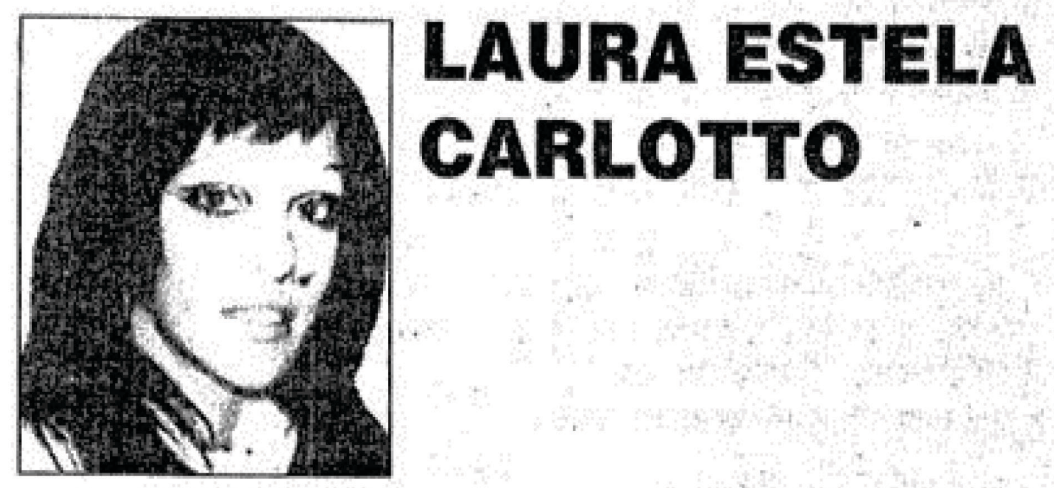

Secuestrada embarazada el 26/11/77. Despojada de su hijo en cautiverio. Asesinada el 25 de agosto de 1978.

20 años de ausencia - 20 años de presencia

Tu valor nos convóca dia a dia a vivir junto a tu rebeldia por las injusticias que soporta el pueblo. Nada mitiga el dolor, en cambio el tiempo refuerza nuestras convicciones. $Y$ por estar convencidas y creer como dijste que tanta muerte no seria en vano es que luchamos por la justicia social, la verdad histórica y la implacable justicia para los responsables de tanto despojo.

Nada ha sido en vano, Laura.

Tu y todos los compañeros están presentes en este pueblo por el que dieron la vida. Nunca olvidaremos. Nunca te olvidaremos.

Tus padres, hermanos, familia y tu hijo Guido desde donde esté. 
ANEXO C - Último recordatorio publicado - No 27 (R.2014)

\section{LAURA ESTELA CARLOTTO \\ Detenida desparecida embarazada el 26 de noviembre de 1977 , junto a su esposo Walmir Oscar Montoya. \\ Asesinada el 25 de agosto de 1978 .}

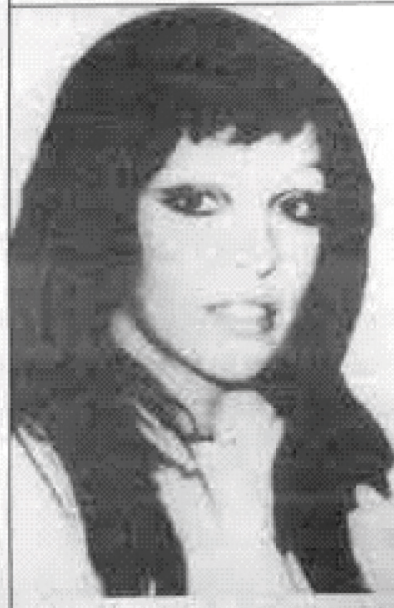

Se cumplen 36 años de tu muerte injusta pero hoy quiero recordar tu vida. Marco ef año de tu nacimiento, 1955 , un nuevo y aberrante atentado a la democracia por parte de los civiles y militares apatridas. Bombardeos, fusilamientos, proscripciones.

Creciste y viviste como apurada, querias modificar el destino de la Patria. Luchar por ta justicia social fue tu lema. Amaste y fuiste amada, y por amor concebiste a tu hijo Guido, dentro de un proyecto de vida junto a Walmir, tu compañero de militancia e ideales.

Cautiva por nueve meses, diste a luz a tu hijo Guido el 26 de junio de 1978 al que acunaste por sólo cinco horas. Lo arrebataron para un destino incierto. Pero la vida nos ha premiado con su encuentro y el 5 de agosto pudimos abrazarlo.

Quiero entonces, querida hija, recordarte viva.

Tendré que despedirme de estos recordatorios. Este serä el ültimo porque estás viva en Guido, hoy estás con nosotros porque regresaste en él y desde alguna estrella brillará tu sonrisa y dirá tu destello: "iMamá, hermanos, misión cumplidal" 